\title{
Impacts of Exchange Rate Volatility and FDI on Technical Efficiency-A Case Study of Vietnamese Agricultural Sector
}

\author{
Nguyen Khac Minh', Pham Van Khanh'2, Nguyen Viet Hung ${ }^{3}$ \\ ${ }^{1}$ Economics and Management Faculty, Thang Long University, Hanoi, Vietnam \\ ${ }^{2}$ Institute of Economics and Corporate Group, Hanoi, Vietnam \\ ${ }^{3}$ Faculty of Economics, National Economics University, Hanoi, Vietnam \\ Email: van khanh1178@yahoo.com
}

Received 24 June 2015; accepted 18 July 2015; published 21 July 2015

Copyright (C) 2015 by authors and Scientific Research Publishing Inc.

This work is licensed under the Creative Commons Attribution International License (CC BY).

http://creativecommons.org/licenses/by/4.0/

c) (i) Open Access

\section{Abstract}

The objective of this research is to examine impacts of exchange rate volatility and FDI on efficiency of the Vietnamese agricultural sector at the provincial level for the period 1998-2011. Due to the characteristic of high uncertainty in agricultural production, the chance-constrained programming model would be used to estimate efficiency of the agricultural production sector. In order to study impacts of exchange rate volatility and FDI, we employ the two-stage model. In the first stage, we use the chance-constrained programming model to measure technical efficiency and ARIMA model to quantify exchange rate volatility. In the second stage, we use the fixed effect model to evaluate impacts of exchange rate volatility and FDI on efficiency of agricultural production in poor and rich provinces. The estimated results show that fluctuation in exchange rate volatility would reduce efficiency in agricultural production but FDI has an insignificant impact on the efficient production in Vietnam agricultural sector.

\section{Keywords}

Chance-Constrained Programming, DEA, Exchange Rate Volatility, FDI, Technical Efficiency

\section{Introduction}

After economic transformation, Vietnam, which was the rice importer before 1980, has become the third largest rice exporter in the world in 1989. The volume of rice exports increased from 2 million tons in 1990 to over 3.6 million tons in 2000. The major rice importers of Vietnam consist of China, Malaysia, Singapore, Indonesia, 
Hong Kong (China), and East Timor. In 2010, India and Thailand were the two largest rice exporters in the world while Vietnam was at the third position. In 2011, Vietnam exceeded Thailand in terms of volume of rice exports to become the second largest after India. However, in terms of value of rice exports, Vietnam is still behind Thailand because the quality of exported rice from Vietnam is lower than one of Thailand, and thereby the price is also lower.

Red river and Mekong river deltas are two major areas of rice exportation in Vietnam. Even though these two deltas account for only $15 \%$ of total area square of the whole country, the volume of rice production is two third of the one of the whole country. The Red river delta contributes to $16.7 \%$ of total volume of rice exportation of Vietnam.

The volume of rice exportation increases over time; however, the value of exportation is not quite high. One of the main reasons is the low quality of Vietnamese rice which could not satisfy the requirement of customers in the world. There have been several researches of efficiency in food production in Vietnam. For instance, Minh and Long (2009) in [1] have employed stochastic frontier approach and non-parametric method to estimate efficiency in agricultural production in Vietnam, using the data at the provincial level in the period 1990-2005. They came to the conclusion that the average technical efficiency, allocation efficiency, and economic efficiency in agricultural production were not high. Minh and Khanh (2011) in [2] have employed the chance-constrained programming model to study productivity growth and efficiency at the provincial level in Vietnam in the period 1995-2007. These researches, however, still separated the efficiency in agricultural production from the overall economic environment. The authors have not taken the characteristic of being rice exporter of Vietnam into consideration. Therefore, they ignored the impacts of exchange rate volatility on rice exporters (or provinces exporting rice) as well as the fact that Vietnam is one of countries attracting a large amount of FDI. This research, thereby, would be different from earlier researches by examining the environment of agricultural production in three aspects:

1) The first issue is that the output of agricultural production is uncertain. The agricultural production can be influenced by several stochastic factors such as weather condition and they can cause a serious damage to agricultural production. This research would not bring the factors of climate change into the model but it still considers the output of agricultural production being uncertain and models them under the chance-constraints.

2) The second issue is that the efficiency of agricultural production could be significantly affected by exchange rate volatility. This argument implies that surprising changes in exchange rate would have impact on decisions of rice exportation because of direct impacts of exchange rate on inputs such as fertilizer, pesticide, seed... and on supply of rice for exportation; hence they would affect production efficiency. This argument is quite close to ones of Ethier (1973) in [3], Clark (1973) in [4], Demers (1991) [5] while they study impacts of exchange rate volatility on trade flows. However, our goal here is to study in more depth impacts of exchange rate volatility on agricultural production, and more particularly rice production. So, our analysis and model derive from the fact that Vietnam is both the importer of input factors for agricultural production and rice exporter. Thereby, exchange rate volatility would have impact on agricultural production through two channels: indirect and direct impacts. The indirect impact on output of agricultural production is through the channel of imported inputs for agricultural production while the direct impact is the change in price of exported rice, which in turn influences the supply capacity of rice of farmers. So, changes in exchange rate can have negative effects on efficiency of agricultural production. The rice production for exportation is mostly concentrated in two areas: Red river delta and Mekong river delta. Therefore, in the model, we must take this characteristic into consideration to study impacts of exchange rate on efficiency of agricultural production among provinces.

3) The third issue is to examine differences in terms of effects of FDI flows on efficiency in agricultural production between rich and poor provinces.

As known so far, many countries try to attract FDI by undertaking different packages of policies because they expect that FDI inflow could bring new technology, know-how and contribute to improvement in productivity and competitiveness of domestic industries. They grant foreign enterprises favorable treatments such as subsidy or favorable tax treatment because policymakers believe that FDI can bring positive externalities to the economy (Caves $(1974,1996)$ in [6] and [7], Findlay (1978) in [8]) through spread of production know-how and technology (Borensztein et al. (1998) in [9], Rappaport (2000) in [10]), thereby, promoting the development of the host country. FDI helps increase amount of capital and employment in the economy (Noorzoy, 1979 in [11]); encouraging technology advance by absorbing foreign technology and the spread of production know-how and technology can occur through granted agreement, imitation, labor training, and application of new processes and 
products. It is believed that FDI would enhance the existing knowledge in the economy through labor training, absorbing and spreading skills (Van Loo 1997 in [12]; Borensztein, De Gregorio and Lee 1998 in [9]; de Mello $1999 i[13] . .$.$) . FDI contributes to bring new more efficient method of management and organization of produc-$ tion process. FDI also helps increase exports of the host country. Therefore, FDI can play an important role in modernizing the economy and promoting the economic development. However, there also has been point of views that FDI can have negative impacts on economic growth due to weak absorbability, the crowding-out effect on domestic investment, more dependence on foreign investors, severe competition between multinational and domestic enterprises, or break of balance of payments when profit could be returned back to the home country. Because of low FDI into agriculture, spill-over effects in agricultural sector, if have, would be small. This feature can be checked with data of Vietnam in the period 1998-2012.

All issues above would be brought in different ways into the model.

\section{Methodology}

All issues mentioned above would be presented in this section. Firstly, we would model the uncertainty of output in agricultural sector by chance-constrained data envelopment model (CCDEA) to estimate efficiency, productivity growth in agriculture of sixty provinces in Vietnam. Then, models to evaluate impacts of exchange rate volatility and foreign direct investment on efficiency of agricultural production sector in Vietnam would be given.

\subsection{A Programming Model with Chance-Constraints to Estimate Efficiency}

We consider a set of $N$ provinces, each consuming amounts of $P$ inputs to produce $M$ outputs. Assuming that each provinces has at least one positive input and one positive output and we can construct the production frontier

$$
H=\left\{(X, Y): X \geq \sum_{r=1}^{N} X_{i r} z_{r}, Y \leq \sum_{r}^{N} Y_{i r} z_{r}, \sum_{r 1}^{N} z_{r}=1, z \geq 0, r=1,2, \cdots, 60\right\}
$$

$H$ satisfies the free disposability of inputs and outputs and includes all provinces.

\subsubsection{Data Envelopment Analysis}

The CRS input-oriented measured of technical efficiency for the $r_{0}$ th province is calculated as solution to the following mathematical programming problem:

$$
\begin{aligned}
\lambda_{c}^{r_{0}} & =\operatorname{Min}_{\lambda, z} \lambda \\
\text { s.t. } & y_{i, r_{0}} \leq \sum_{r=1}^{N} y_{i, r} z_{r} ; i=1,2, \cdots, M \\
& \sum_{r=1}^{N} x_{j, r} z_{r} \leq \lambda x_{j, r_{0}}, j=1,2, \cdots, P \\
& z \in R_{+}^{N}
\end{aligned}
$$

The scalar value $\lambda$ represents a proportional reduction in all inputs such that $0 \leq \lambda \leq 1$, and $\lambda_{c}^{r_{0}}$ is the minimum value of $\lambda$ so that $\lambda_{c}^{r_{0}} X_{r}$ represents the vector of technically efficient inputs for the $r_{0}$ th provinces.

Maximum technical efficiency is achieved when $\lambda_{c}^{r_{0}}$ is equal to utility. In other words, according to the DEA result when $\lambda_{c}^{r_{0}}$ is equal to utility, a province is operating at best-practice and cannot improve on this performance under the condition of the existing set of observations.

\subsubsection{Data Envelopment Analysis with Stochastic Constraints (Chance-Constrained Programming Model-CCDEA)}

There are several papers about efficiency which employ chance-constrained programming model. Land et al. (1993) in [14] examines the basic chance-constrained programming model to estimate production efficiency in the case that inputs and outputs are stochastic. Copper et al. (2004) in [15] employs the programming approach with stochastic constraints to study congestion in stochastic DEA. Chen (2004) in [16] uses the DEA approach in deterministic and stochastic forms to measure technical efficiency of commercial banks in Taiwan in the pe- 
riod of financial crisis. The author finds that the score of technical efficiency from the deterministic form of DEA approach is higher than one from the stochastic form. Chen (2005) also uses the stochastic DEA approach and stochastic frontier analysis to measure technical efficiency of 39 commercial banks in Taiwan. The author shows that there is a significant difference between efficiency estimated from DEA model with stochastic constraints and one from stochastic frontier production function. Minh et al. (2011) in [2] uses the programming approach with stochastic constraints to decompose total factor productivity change (tfpch) into efficiency change (effch) and technical change (techch) in the Vietnamese agriculture sector for the period 1995-2007. The DEA model with stochastic constraints would have three following assumptions:

Assumption 1: Stochastic output.

Based on DEA model mentioned above, we assume that the probability that the best practical agricultural output exceeds the observed output must not be less than $\alpha$. In other words, the constraint

$$
y_{i, r_{0}} \leq \sum_{h=1}^{N} y_{i, r} z_{r}, i=1,2, \cdots, M
$$

can be converted to the following constraint:

$$
p\left[y_{i, r_{0}} \leq \sum_{h=1}^{N} y_{i, r} z_{r}\right] \geq \alpha, i=1,2, \cdots, M .
$$

Thus, corresponding chance-constrained efficiency measure is calculated as:

$$
\begin{aligned}
\lambda_{c}^{r_{0}} & =\operatorname{Min}_{\lambda, z} \lambda \\
\text { s.t. } & \operatorname{prob}\left[\sum_{h=1}^{N} y_{i, r} z_{r} \geq y_{i, r_{0}}\right] \geq \alpha ; i=1,2, \cdots, M \\
& \sum_{r=1}^{N} x_{j, r} z_{r} \leq \lambda x_{j, r_{0}}, j=1,2, \cdots, P \\
& z \in R_{+}^{N}
\end{aligned}
$$

Assumption 2: $y_{m, k}$ has normal distribution with mean being $E\left(y_{m, k}\right)$ and variance being $\operatorname{var}\left(y_{m, k}\right)$.

Assumption 3: All outputs of provinces are randomly independent and $\operatorname{var}\left(y_{m, k}\right)=1$ (for all $k=1,2, \cdots, \mathrm{M}$ ) and $\operatorname{cov}\left(y_{m, h}, y_{m, k}\right)=0$ for $h \neq k$. We apply the method introduced by Minh et al. (2011) to solve problems (4) and to measure TE.

\subsubsection{Test Difference between the Average Efficiency Scores of CCDEA and DEA}

We use two Banker's asymptotic DEA efficiency tests to test for inefficiency differences between two different efficiency scores:

1) The two inefficiency scores $\left(1-\theta_{\mathrm{CCDEA}}\right)$ and $\left(1-\theta_{\mathrm{DEA}}\right)$ follow the exponential distribution.

The test statistic is: $\frac{\frac{\sum_{i=1}^{N_{\text {CCDEA }}}\left(1-\theta_{i, \text { CCDEA }}\right)}{N_{\text {CCDEA }}}}{\frac{\sum_{i=1}^{N_{\text {DEA }}}\left(1-\theta_{i, \text { DEA }}\right)}{N_{\text {DEA }}}}$ evaluated relative to the $F$-distribution with $\left(2 N_{\text {CCDEA }}, 2 N_{\text {DEA }}\right)$ degrees of freedom.

2) The two inefficiency scores $\left(1-\theta_{\text {CCDEA }}\right)$ and $\left(1-\theta_{\mathrm{DEA}}\right)$ follow the half-normal distribution, the test sta-

tistic is $\frac{\frac{\sum_{i=1}^{N_{\text {CDDEA }}}\left(1-\theta_{i, \text { CCDEA }}\right)^{2}}{N_{\text {CCDEA }}}}{\frac{\sum_{i=1}^{N_{\text {DEA }}}\left(1-\theta_{i, \text { DEA }}\right)^{2}}{N_{\text {DEA }}}}$ evaluated relative to the $F$-distribution with $\left(N_{\text {CCDEA }}, N_{\text {DEA }}\right)$ degrees of freedom. 


\subsection{Impacts of FDI Flow on Efficiency of Agricultural Sector}

To analyze impacts of FDI on technical efficiency in agricultural production, two variables are included: FDI represents the FDI inflow to each province in the period 1998-2011. This variable can reflect impacts of vertical spillover of FDI to agricultural production of provinces. The second variable FDI* $\mathrm{G}$ is the product of dummy variable $\mathrm{G}$ (taking value of 1 if that is a rich province and 0 if not). The reason for constructing this variable includes: 1) firstly, it can be shown that rich provinces have more FDI enterprises than poor ones have, 2) theoretically, richer provinces have more advantages in capacity of absorbing spillover effects of FDI.

\subsection{Impacts of Exchange Rate Volatility on Efficiency of the Agricultural Sector}

There have been a lot of researches concerned with impacts of exchange rate volatility on trade flows. Many measurements of exchange rate volatility have been used. For instance, Thursby and Thursby in [17] use the absolute percentage change of exchange rate, i.e. $\left\{\left(V_{t}=\left|\left(e_{t}-e_{t-1}\right)\right| / e_{t-1}\right)\right.$, in which $e_{t}$ is the spot rate and $t$ represents the period $\}$ as the measurement of exchange rate volatility. McIvoi [18] use residuals from ARIMA model as the measurement of exchange rate volatility. McKenzie [19] use ARCH model to quantify the volatility of exchange rate.

In this research, exchange rate volatility is measured by residuals from ARIMA model. The exchange rate volatility is estimated from quarterly data, however data used to estimate the model of evaluating impacts of exchange rate on efficiency are only available at the annual frequency. Thereby, we would use the two-step procedure to select proxy variable for exchange rate volatility.

1) Estimation of ARIMA $(p, q, d)$

$$
\Delta^{d} e x_{t}=\alpha_{1} \Delta^{d} e x_{t-1}+\cdots+\alpha_{p} \Delta^{d} e x_{t-p}+u_{t}+m_{1} u_{t-1}+\cdots+m_{q} u_{t-q}+C D_{t}
$$

in which $p$ is the autoregressive order, $q$ is the moving average order, and $d$ is the degree of difference.

$e x_{t}$ is the real exchange rate and $\Delta$ is the difference operator defined as follow:

$$
\Delta^{d} e x_{t}=\Delta\left(\Delta^{d-1} e x_{t}\right), d \geq 2 ; \quad \Delta e x_{t}=e x_{t}-e x_{t-1}
$$

The vector $D_{t}$ consists of deterministic terms such as constant, linear trend, dummy variables... and $u_{t}$ is the white noise process with expected value 0 and variance $\sigma_{u}^{2}$.

2) From residuals $e_{t}$ of the estimated model $\operatorname{ARIMA}(p, q, d)$, we pick up three values each year

$$
\begin{aligned}
& e_{t, \text { max }}=\operatorname{Max}\left\{e_{t \mathrm{I}}, e_{t \mathrm{II}}, e_{t \mathrm{tII}}, e_{t \mathrm{IV}}\right\}, \text { denoting } \sigma_{e 1} ; \\
& e_{t, \text { min }}=\operatorname{Min}\left\{e_{t \mathrm{t}}, e_{t \mathrm{II}}, e_{t \mathrm{III}}, e_{t \mathrm{IV}}\right\}, \text { denoting } \sigma_{e 2} ; \\
& e_{t, \text { average }}=\text { Average }\left\{e_{t \mathrm{tI}}, e_{t \mathrm{II}}, e_{t \mathrm{tII}}, e_{t \mathrm{IV}}\right\},
\end{aligned}
$$

denoting $\sigma_{e 3}$, in which $e_{\mathrm{tI}}, e_{\mathrm{tII}}, e_{\mathrm{tIII}}, e_{\mathrm{tIV}}$ are residuals $e_{t}$ of the model ARIMA $(p, q, d)$ in year $t$, quarter I, quarter II, quarter III and quarter IV respectively.

Then, we can establish the series $\left\{\sigma_{e 1}\right\},\left\{\sigma_{e 2}\right\}$ and $\left\{\sigma_{e 3}\right\}$. These series correspond to three models, in which the models differ from each other at the way to measure exchange rate volatility. The exchange rate volatility in each model can be estimated from a pair of variables $\sigma_{e}$ and $\sigma_{e N}$. The variable $\sigma_{e}\left\{\left(\sigma_{e 1}\right),\left(\sigma_{e 2}\right)\right.$, and $\left.\left(\sigma_{e 3}\right)\right\}$ shows exchange rate volatility while $\sigma_{e N}$ is the product of two variables $e$ and $n$, in which nis the dummy variable taking value of 1 in the case of poor province, i.e. having income lower than the average level of the whole country. This variable $\left(\left\{\sigma_{e 1 n}\right\},\left\{\sigma_{e 2 n}\right\}\right.$ and $\left.\left\{\sigma_{e 3 n}\right\}\right)$ would help us examine impacts of exchange rate on poor provinces.

\subsection{Effects of Exchange Rate Volatility, FDI and Other Factors on Efficiency in Agricultural Production}

To study impacts of exchange rate volatility and FDI on efficiency in agricultural production, we employ fixed effect model to evaluate impacts of exchange rate volatility $\left(\sigma_{e}\right)$, FDI, FDIG and $\sigma_{N}$ on variables TECCDEA. The model can be specified as follow:

$$
\mathrm{TECCDEA}_{i, t}=\alpha_{i}+\alpha_{1} \mathrm{FDI}_{i, t}+\alpha_{2}\left(\frac{K}{L}\right)_{i, t}+\alpha_{3} \sigma_{e t}+\alpha_{4} \mathrm{FDIG}_{i, t}+\alpha_{5} \sigma_{e N_{i, t}}+\varepsilon_{i, t}
$$


with $i$ denoting provinces, and $t$ denoting time periods. The dependent variable TECCDEA $\mathrm{A}_{i, t}$ is the annual technical efficiency of $i$ th province at time $t$, estimated from CCDEA model. $\left(\frac{K}{L}\right)_{i, t}$ is the capital-labor ratio of $i$ th province at time $t . \mathrm{FDI}_{i, t}$ is foreign direct investment in ith province at time $t . \sigma_{e t}$ (residuals) represents exchange rate volatility in year $t$, estimated from $\operatorname{ARIMA}(p, q, d)$ model. FDIG $_{i, t}$ is foreign direct investment in the rich province at year $t . \sigma_{e N_{i, t}}$ expresses the impacts of exchange rate volatility on poor provinces at time $t$.

There are three forms of model (7). Model (7a) ((7b) and (7c)) is model (7) with $\sigma_{e}$ in (6a) ((6b) and (6c)).

The parameter $\alpha_{i}$ may have two different interpretations and two different models may be distinguished according to this interpretations. If the $\alpha_{i}$ is assumed to be fixed parameters, Equation (6) is a fixed effect panel data model. Conversely, if the $\alpha_{i}$ are assumed to be random, Equation (6) is a random effect panel data model. In general, fixed effect model is indicated when the regression analysis is limited to a precise set of individuals. For this reason, since our data set consists of the observations over the 60 provinces, we use a fixed effect panel data model to analyze the impacts of exchange rate volatility and FDI on technical efficiency from CCDEA model in agricultural production.

\section{Data Source}

Data set used in this research consists of inputs and outputs of agricultural production in sixty provinces in Vietnam in the period 1998-2011. Data of some provinces must be added up due to separation or combination between provinces in this period. For instance, Ha Tay and Hanoi are two separated provinces before 2008, but then they are combined with each other to become new Hanoi. Therefore, statistical data for HaTay would not be available since then. To ensure the consistency of data, we would add up each indicator of HaTay to the corresponding indicator of Hanoi in the period 1998-2008, and now we have new data set for only one province, namely new Hanoi. We do the same transformation for two other pairs of provinces including Dac Lac and Dac Nong, Dien Bien and Lai Chau. The data set used in this research is collected from General Statistical Office and Ministry of Labor-Invalids and Social Affairs.

Most of researches about agricultural productivity in Vietnam use gross value of agricultural value as gross value of agricultural production. The gross value of agricultural value is defined as the gross value of agricultural production in following fields: cultivation, forestry, animal husbandry, fishery, and secondary works. The value of all inputs in agricultural production would also be included in the gross value of Vietnamese agricultural value. Thereby, in this research, the net value or added value of agricultural output (VAO) would be used to measure gross value of Vietnamese agricultural output. The VAO data of provinces in the period 19988-2011 would be adjusted with respect to GDP deflator, in which base year is 1994. The quarterly exchange rate (VND/\$) data in the period 1995-2012 and the data of implemented FDI in the period 1998-2011 are collected from General Statistical Office.

\section{Estimation Results}

\subsection{The Estimated Results of Efficiency in Agricultural Production of Provinces from CDEA}

We employ the indicator, namely inverse of (2), to measure technology efficiency in agricultural sector for each province in Vietnam in the period 1998-2011. These values of technical efficiency are measured under the assumption of constant returns to scale within sixty provinces in the period 1998-2011.

To have a preliminary picture of technical efficiency in agricultural sector, we would firstly review estimated results of efficiency of provinces in this period. The results show that agricultural production in Ho Chi Minh city has efficiency score lying in the group of ten best provinces within 12 years, and lying on the frontier curve in 9 years. Agricultural production in Tra Vinh also has efficiency score lying in the group of ten best provinces within 12 years, but only lying on the frontier curve in 5 year. Agricultural production in Ba Ria-Vung Tau has efficiency score lying in the group of ten best provinces within 10 years, and lying on the frontier curve in 4 years. Efficiency score of agricultural production of Ben Tre belongs to the group of ten best in 9 years and lies on the frontier curve in 4 years... In contrast, the group of ten least efficient provinces in agricultural production includes provinces such as Quang Ninh and Dien Bien (in 13 years), Thai Nguyen and Quang Binh (in 12 years), Ha Giang and Phu Yen (in 11 years). Especially, Phu Tho has lowest efficiency score of agricultural production 
within 13 years but in 2011, it steps up to become one of the ten most efficiency in terms of agricultural production. Quang Ngai also lies in the group of ten least efficiency in 1998 but jumps up to the group of ten most efficiency in 2011.

\subsection{Estimated Results of Efficiency Tests between Two Different Scores from CCDEA and DEA Model}

To compare between technical efficiency estimated from CCDEA model and technical efficiency estimated from DEA model, we use two Banker's asymptotic DEA efficiency tests.

The estimated results of two Banker's asymptotic DEA efficiency tests can be given in Table 1.

The test statistics estimated under the assumption of the two inefficiency scores following the exponential distribution (the half-normal distribution) are reported in the second column (the fourth column) in Table 1 and the critical value in the third column ( the fifth column). The both types of test results show that there is no significant difference between the average efficiency scores of DEA and chance-constrained DEA methods. We can conclude that the chance-constrained DEA model measurement does not have a different between the DEA and chance-constrained DEA model measurement. The difference between two models can be explained as: the CCDEA model involves only the probabilistic structure of agricultural sector output, and flexible production frontier may occur.

\subsection{Evaluating Impacts of Exchange Rate and FDI Flow on Efficiency}

We conduct a regression analysis to determine the impacts of exchange rate volatility and FDI flow on technical efficiency in Vietnam agricultural sector. Table 2 presents estimation results of fixed-effect model using panel data.

The first column in this table shows the name of variables in the models. The third, fourth, and fifth column give estimation results from three models in which efficiency scores estimated from CCDEA model. All three models have the same independent variables except exchange rate. In the first model, the maximum exchange rate $\left(\sigma_{e 1}\right)$ is used, and in the second model the minimum exchange rate $\left(\sigma_{e 2}\right)$ is used and in the third one, the average exchange rate $\left(\sigma_{e 3}\right)$ is used.

Table 1. Summary of efficiency difference test results (CCDEA vs. DEA).

\begin{tabular}{|c|c|c|c|c|}
\hline Year & Exponential type & Critical value & Half-normal type & Critical value \\
\hline 1998 & 0.9602 & 1.5330 & 1.2778 & 1.8360 \\
\hline 1999 & 0.8646 & 1.5330 & 1.2250 & 1.8360 \\
\hline 2000 & 1.0395 & 1.5330 & 1.3134 & 1.8360 \\
\hline 2001 & 1.063 & 1.5330 & 1.3644 & 1.8360 \\
\hline 2002 & 1.1131 & 1.5330 & 1.3784 & 1.8360 \\
\hline 2003 & 1.0593 & 1.5330 & 1.3501 & 1.8360 \\
\hline 2004 & 1.0288 & 1.5330 & 1.3294 & 1.8360 \\
\hline 2005 & 1.0179 & 1.5330 & 1.3001 & 1.8360 \\
\hline 2006 & 1.0311 & 1.5330 & 1.3080 & 1.8360 \\
\hline 2007 & 0.999 & 1.5330 & 1.3005 & 1.8360 \\
\hline 2008 & 0.9565 & 1.5330 & 1.2659 & 1.8360 \\
\hline 2009 & 0.8596 & 1.5330 & 1.2187 & 1.8360 \\
\hline 2010 & 0.8219 & 1.5330 & 1.2043 & 1.8360 \\
\hline 2011 & 1.0016 & 1.5330 & 1.3144 & 1.8360 \\
\hline
\end{tabular}

Source: The authors estimate from the data of GSO. 
Table 2. The estimation results of fixed-effect model for.

\begin{tabular}{cccc}
\hline & & Chance-constrained model & \\
\cline { 2 - 3 } FDI & Model (7a) & Model $(7 \mathrm{~b})$ & Model $(7 \mathrm{c})$ \\
K/L & $0.00026(0.00002)$ & $0.000267(0.00002)$ & $0.000018(0.00002)$ \\
$\sigma_{e}$ & $1.3882^{* * *}(0.3118)$ & $1.4055^{* * *}(0.3139)$ & $1.4688^{* * * *}(0.3155)$ \\
FDIG & $-2.0277^{* * *}(0.3128)$ & $-1.7632^{* * *}(0.3222)$ & $-4.4618^{* * *}(0.7945)$ \\
$\sigma_{\text {en }}$ & $-0.00004(0.00003)$ & $-0.00004(0.00003)$ & $-0.00004(0.00003)$ \\
cons & $1.1293^{*}(0.6271)$ & $0.7733(0.7869)$ & $5.7488^{* * *}(1.6723)$ \\
/sigma_u & $0.5077^{* * *}(0.0055)$ & $0.5003^{* * *}(0.0050)$ & $0.4882^{* * *}(0.0044)$ \\
/sigma_e & 0.2242 & 0.2251 & 0.2250 \\
Rho & 0.1139 & 0.1148 & 0.1147 \\
$\mathrm{R}^{2}$ : within & 0.7946 & 0.7936 & 0.7936 \\
Between & 0.0775 & 0.0641 & 0.0653 \\
overall & 0.0446 & 0.0095 & 0.0133 \\
Number of obs & 0.0267 & 0.0169 & 0.0181 \\
\hline
\end{tabular}

Source: The authors estimate from the data of GSO.

The estimation results show that in all three models, the coefficient of exchange rate variable $\left(\sigma_{e}\right)$ takes negative value and highly statistical significance. This implies that fluctuation in exchange rate would reduce efficiency in agricultural production. This can be explained by the fact that a large proportion of agricultural production in Vietnam is rice, whose export value is very large. Exchange rate volatility can directly affect exports. This result is compatible with theoretical view that exchange rate volatility would reduce trade flow. This view claims that a sudden change in exchange rate would have effect on decision of risk-adverse traders, therefore volume of trade would decline. This view is also given in Ethier [3] published soon after the breakdown of Bretton-Woods system. Clark [4] develops a similar model for a risk-adverse firm and comes to the same conclusion. Meanwhile, the sign of variable $\sigma_{e n}$ is positive and statistically significant (except in the model 2), which means that exchange rate volatility in the case of provinces having no rice exports has positive impacts on efficiency. The possible reason is that exchange rate volatility often makes imported agricultural materials cheaper, so provinces without rice export would benefit due to lower input costs, so the product of these two variables would take positive value and be highly statistically significant.

The estimation results of FDI variable in all three models take positive value but insignificant at the any level. The sign of the variable GFDI is negative and insignificant. It means that FDI flow during the period of 19882011 have not been significant impact on the efficient production in Vietnam agricultural sector.

\section{Conclusions}

This research employs chance-constrained DEA approach to estimate technical efficiency in Vietnamese agriculture sector in the period 1998-2011.

This research examines effects of exchange rate volatility and FDI flows on efficiency of production in agriculture sector by using residuals from ARIMA model as proxy variable for exchange rate volatility. By dividing provinces in the country into two groups, namely rich and poor one, we can derive several interesting findings. The results show that in all three models, the coefficient of exchange rate variable is negative and highly statistically significant, that is, fluctuation of exchange rate would reduce efficiency of production in agriculture production. However, exchange rate volatility in provinces without rice exportations has a positive impact on efficiency. The coefficient of FDI variable is positive and insignificant at any level. Meanwhile, the coefficient of FDIG variable is negative and insignificant. 


\section{References}

[1] Minh, N.K. and Long, G.T. (2009) Efficiency Estimates for the Agricultural Production in Vietnam: A Comparison of Parametric and Non-Parametric Approaches. Agricultural Economics Review, 10, 62-78.

[2] Minh, N.K. and Khanh, P.V. (2011) A Chance-Constrained Data Envelopment Analysis Approach to Problem Provincial Productivity Growth in Vietnamese Agriculture from 1995 to 2007. Open Journal of Statistics, 1, 217-235. http://dx.doi.org/10.4236/ojs.2011.13026

[3] Ethier, W. (1973) International Trade and the Forward Exchange Market. American Economic Review, 63, $494-503$.

[4] Clark, P.B. (1973) Uncertainty, Exchange Risk, and the Level of International Trade. Western Economic Journal, 11, 302-313. http://dx.doi.org/10.1111/j.1465-7295.1973.tb01063.x

[5] Demers, M. (1991) Investment under Uncertainty, Irreversibility and the Arrival of Information over Time. Review of Economic Studies, 58, 333-350. http://dx.doi.org/10.2307/2297971

[6] Caves, R. (1974) Multinational Firms, Competition and Productivity in the Host Country. Economics, 41, $176-193$. http://dx.doi.org/10.2307/2553765

[7] Caves, R. (1996) Multinational Enterprise and Economic Analysis. Cambridge University Press, Cambridge.

[8] Findlay, R. (1978) Relative Backwardness, Direct Foreign Investment and the Transfer of Technology: A Simple Dynamic Model. Quarterly Journal of Economics, 92, 1-16. http://dx.doi.org/10.2307/1885996

[9] Borensztein, E.J., DeGregorio, J. and Lee, J.W. (1998) How Does Foreign Direct Investment Affect Economic Growth? Journal of International Economics, 45, 115-135. http://dx.doi.org/10.1016/S0022-1996(97)00033-0

[10] Rappaport, J. (2000) How Does Openness to Capital Flows Affect Growth? Research Working Paper, RWP00-11, Federal Reserve Bank of Kansas City.

[11] Noorzoy, M.S. (1979) Flows of Direct Investment and Their Effects on Investment in Canada. Economic Letters, 2, 257-261. http://dx.doi.org/10.1016/0165-1765(79)90032-6

[12] Van Loo, F. (1977) The Effect of Foreign Direct Investment on Investment in Canada. Review of Economics and Statistics, 59, 474-481. http://dx.doi.org/10.2307/1928712

[13] De Mello Jr., L. (1999) Foreign Direct Investment-Led Growth: Evidence from Time Series and Panel Data. Oxford Economic Papers, 51, 133-151. http://dx.doi.org/10.1093/oep/51.1.133

[14] Land, K.C., Knox Lovell, C.A. and Thore, S. (1993) Chance-Constrained Data Envelopment Analysis. Managerial and Decision Economics, 14, 541-554. http://dx.doi.org/10.1002/mde.4090140607

[15] Copper, W.W., Deng, H.Z., Huang, Z. and Li, S.X. (2004) Chance Constrained Programming Approaches to Congestion in Stochastic Data Envelopment Analysis. European Journal of Operation Research, 155, 487-501. http://dx.doi.org/10.1016/S0377-2217(02)00901-3

[16] Chen, T. (2002) A Comparison of Chance-Constrained DEA and Stochastic Frontier Analysis: Bank Efficiency in Taiwan. The Journal of the Operational Research Society, 53, 492-500. http://dx.doi.org/10.1057/palgrave.jors.2601318

[17] Thursby, M.C. and Thursby, J.G. (1985) The Uncertainty Effects of Floating Exchange Rates: Empirical Evidence on International Trade Flows. Ballinger Publishing Co., Cambridge, 153-166.

[18] McIvor, R. (1995) Exchange Rate Variability and Australia’s Export Performance.

[19] McKenzie, M. and Brooks, R. (1997) The Impact of Exchange Rate Volatility on German-US Trade Flows. Journal of International Financial Markets, Institutions and Money, 7, 73-87. http://dx.doi.org/10.1016/S1042-4431(97)00012-7 